DOI: https://doi.org/10.36910/6775-2524-0560-2021-43-26

УДК 543.06

Шорнікова Світлана Василівна, начальник відділу

https://orcid.org/0000-0002-9038-2457

Український науково-дослідний інститут спеціальної техніки та судових експертиз Служби безпеки України, м. Київ

\title{
ВАЛІДАЦІЯ ТА ВЕРИФІКАЦІЯ МЕТОДИК ВИМІРЮВАННЯ ГЕОМЕТРИЧНИХ РОЗМІРІВ В УМОВАХ ВИРОБНИЦТВА
}

\begin{abstract}
Шорнікова С.В. Валідація та верифікація методик вимірювання геометричних розмірів в умовах виробництва. Описано принципи валідації та верифікації методик вимірювання геометричних розмірів в умовах виробництва. Зазначається, що виготовлена деталь перевіряється за допомогою вимірювального пристрою і порівнюється 3 еталоном з метою перевірки специфікацій розмірів та геометричних характеристик (фактичний розмір і допуск), а потім відхилення обчислюються та відображаються. Представлена модель налаштування процесу перевірки в якій схематично наведено всі етапи верифікації. Сформовано визначення основних понять, так валідація - верифікація, при якій встановлені вимоги пов'язані з передбачуваним використанням; валідація методик вимірювань - це процес підтвердження, через приведення об'єктивних доказів, як правило, отриманих експериментальним шляхом, того, що методику можна використовувати для певного призначення, а верифікація - надання об'єктивних доказів того, що даний об'єкт повністю відповідає встановленим вимогам. Математично обгрунтовано принцип формування вимірювальної величини та комбінованої стандартної невизначеності. Описано метод Монте-Карло, який зазвичай використовується для наближення статистичної поведінки вимірюваної величини в ситуаціях, коли функцію вимірювання неможливо знайти безпосередньо. Наведено модель налаштування комп'ютерної результуючої системи геометричних вимірів та описано концептуальну основу для перевірки моделі системи геометричних вимірів, яка включає п'ять типів дійсності (концептуальний, логічний, типовий, експериментальний, оперативний). Зазначено, що довгострокові переваги використання перевіреної моделі для доповнення фізичного вимірювання повинні бути збалансовані із витратами, пов'язаними з розробкою моделі та моделлю вимірювання геометричних розмірів в умовах виробництва.
\end{abstract}

Ключові слова: валідація, верифікація, методика, вимірювання, геометричні розміри, виробництво, похибка.

Шорникова С. В. Валидация и верификация методик измерения геометрических размеров в условиях производства. Описаны принципы валидации и верификации методик измерения геометрических размеров в условиях производства. Отмечается, что изготовленная деталь проверяется с помощью измерительного устройства и сравнивается с эталоном с целью проверки спецификаций размеров и геометрических характеристик (фактический размер и допуск), а затем отклонения вычисляются и отображаются. Представленная модель настройки процесса проверки, в которой схематично приведены все этапы верификации. Сформирован определения основных понятий, так валидация - верификация, при которой установлены требования связаны с предполагаемым использованием; валидация методик измерений - это процесс подтверждения, через приведение объективных доказательств, как правило, полученных экспериментальным путем, того, что методику можно использовать для определенного назначения, а верификация - предоставление объективных доказательств того, что данный объект полностью соответствует установленным требованиям. Математически обоснованно принцип формирования измеряемой величины и комбинированной стандартной неопределенности. Описан метод Монте-Карло, который обычно используется для приближения статистической поведения измеряемой величины в ситуациях, когда функцию измерения не могут напрямую. Представлена модель настройки компьютерной результирующей системы Измерения и описано концептуальную основу для проверки модели системы Измерения, которая включает пять типов действительности (концептуальный, логический, типичный, экспериментальный, оперативный). Отмечено, что долгосрочные преимущества использования проверенной модели для дополнения физического измерения должны быть сбалансированы с расходами, связанными с разработкой модели и модели измерения геометрических размеров в условиях производства.

Ключевые слова: валидация, верификация, методика, измерения, геометрические размеры, производство, погрешность.

Shornikova Svitlana. Measuring methodologies of geometrical sizes validation and verification in the production conditions. The principles of validation and verification of methods for measuring geometric dimensions in production conditions are described. It is noted that the manufactured part is checked with a measuring device and compared with the standard to check the size specifications and geometric characteristics (actual size and tolerance), and then the deviations are calculated and displayed. A model for setting up the verification process is presented, which schematically shows all the stages of verification. The definition of basic concepts is formed, so validation - verification, in which the requirements are related to the intended use; validation of measurement methods is a process of confirmation, by providing objective evidence, usually obtained experimentally, that the method can be used for a specific purpose, and verification - the provision of objective evidence that the object fully complies with the established requirements. The principle of forming a measurand and a combined standard uncertainty is mathematically substantiated. Describes the Monte Carlo method, which is usually used to approximate the statistical behavior of a measured quantity in situations where the measurement function cannot be found directly. The model of setting up the computer resultant system of geometric measurements is given and the conceptual basis for checking the model of the system of geometric measurements is included, which includes five types of reality (conceptual, logical, typical, experimental, operational). It is noted that the long-term benefits of using a proven model to supplement physical measurement should be balanced with the costs associated with developing a model and model for measuring geometric dimensions in production.

Keywords: validation, verification, method, measurement, geometric dimensions, production, error. 
Вступ та постановка проблеми дослідження. Геометричне вимірювання та допуск (або геометричні специфікації виробу) - це мова символів, що широко використовується в інженерних кресленнях та згенерованих комп'ютером моделях для опису, передачі та визначення допустимих відхилень геометрії об'єктів. Геометричне вимірювання - це ефективний і однозначний спосіб передачі умов вимірювання та специфікацій деталі. Ця мова супроводжує весь ланцюжок процесів і допомагає сформувати поняття про функції деталей шляхом проектування, виготовлення та перевірки. Крім того, вона забезпечує більш точне зображення деталей та фокусується на взаємозв'язку між елементами.

Методики вимірювань - це процес, який має своє певне призначення: отримати інформацію про параметри / показники деякого об'єкта (сировина, продукція, об'єкти навколишнього середовища, біологічний матеріал і т.п.). Отримана в результаті застосування методики вимірювань інформація, для вимірюваних величин виражена у вигляді результату вимірювання, що використовується потім для прийняття управлінських рішень. Щоб прийняти вірне рішення, потрібно довіряти інформації, на підставі якої воно приймається, i, отже, методиці вимірювань, яка цю інформацію надає.

Довіра виражається у вигляді певних вимог, яким повинна відповідати методика вимірювань. Ці вимоги підтверджуються в ході валідації / верифікації методик вимірювань. 3 точки зору метрології поняття валідації та верифікації закріплені в міжнародному словнику по метрології VIM3 [1].

Аналіз останніх досліджень $\boldsymbol{i}$ публікацій. Формування політик, методів та методик застосування валідації та верифікації в умовах виробництва досліджували вчені на протязі багатьох років.

У настанові [2] пояснено поняття "валідація методу", описано, які характеристики визначають під час валідації, як іï проводять, як застосовують результати валідації для внутрішнього контролювання якості, як треба викладати у документах аналітичні методики тощо.

Л.П. Почекайлова [3] розглянула методи валідації випробувань, які розвинуто у міжнародних та європейських нормативних документах та застосовують в акредитованих випробувальних лабораторіях. Авторка подала загальну характеристику різних видів валідації, встановила метрологічні характеристики методів випробувань, які досліджують під час проведення валідації. Застосування методів валідації в лабораторії та документування iï результатів дозволяє гарантувати точність результатів вимірювань, які подає лабораторія, та значно підвищує технічну компетентність лабораторії.

О. Ю. Браілов, В. І. Панченко, С. І. Косенко [4] виконали аналіз геометричної моделі визначення недоступної точки об'єкта. Виявлена проблема і визначені першочергові задачі. Приведене визначення геометричної моделі вимірювань як моделі, що пов'язує вимірювальними приладами візирні промені з ії проекціями та об'єкт дослідження в певній системі координат 3 площинами проекцій.

Iз зарубіжних варто рів варто відзначити такі роботи як: R. Raffaeli, M. Mengoni, M. Germani, F. Mandorli [5], H. Hovind, B. Magnusson, M. Krysell, U. Lund, and I. Makinen [6], Thompson M., Ellison S.L.R. and Wood R. [7], MacKinnon, D., Carrier, B., Beraldin, J.A., Cournoyer, L. [8], Van Loco, J., Elskens, M., Croux, C., Beernaert, H. [9], B. Magnusson, T. Naykki, H. Hovind, M. Krysell [10], Lukacs G., Lockhart J., Facello M. [11], Barbero B.R., Ureta E.S. [12] та інші.

Проте, враховуючи описані наукові набутки, за темою, питання розкриття принципів валідації та верифікації методик вимірювання геометричних розмірів в умовах виробництва залишається відкритим та потребує детального опрацювання.

Mema cmammi. Розкрити принципи валідації та верифікації методик вимірювання геометричних розмірів в умовах виробництва.

Викладення основного матеріалу дослідження. Стандарти ISO-GPS, складаються 3 бібліотеки символів, визначень, правил та конвенцій, що описують частину з точки зору допусків на основі розміру, форми, орієнтації та розташування. Основні та необхідні кроки, потрібні для отримання результатів геометричного вимірювання, починаються з номінальної інформації, яка описує конкретну особливість виробу. Виготовлена деталь перевіряється за допомогою вимірювального пристрою (наприклад, координатно-вимірювальної машини (КВМ)) і порівнюється 3 еталоном (наприклад, файлом автоматизованого проектування (CAD)) 3 метою перевірки специфікацій розмірів та геометричних характеристик (фактичний розмір і допуск). Потім відхилення обчислюються та відображаються. На рисунку 1 представлена модель налаштування процесу перевірки.

У науці про метрологію істинні значення (ідеальні величини) можуть залишатися не відомими, і всі вимірювання можуть мати певну ступінь невизначеності, що часто $є$ функцією декількох змінних (джерел). Різниця між дійсними та виміряними значеннями відома як похибка. Невизначеність параметр, пов'язаний з результатом вимірювання, що характеризує розподіл значень, які можна 
обгрунтовано віднести до вимірюваної величини. Таким чином, розрахункове значення вимірюваної величини Y, як правило, обчислюється з використанням співвідношення, представленого у рівнянні (1)

$$
y=f\left(x_{1}, x_{2}, \ldots, x_{n}\right)
$$

де $x_{i}$-оцінка для кожної вхідної змінної $X_{i}$, яка потенційно може мати значний вплив на результат вимірювання $(y)$. Функція $f$ може бути відомою та явною. Однак у деяких випадках функція вимірювання невідома або дуже складна, і аналітичний вираз недоступний.

Якщо функція $f \in$ явною, а вхідні величинине співвідносяться, закон поширення невизначеностей, наведений у [9], як правило, представляє комбіновану стандартну невизначеність щодо оціненого значення $u(y)$ за:

$$
u(y)=\sqrt{\sum_{i=1}^{n}\left(\begin{array}{l}
\partial f \\
\partial x_{i}
\end{array}\right)^{2} u^{2}\left(x_{i}\right)}
$$

де $u\left(x_{i}\right)$-стандарт на невизначеність кожної вхідної змінно ї $x_{i}$. На практиці розширена невизначеність $U(y)$ відповідає суміщеній стандартній невизначеності, помноженій на коефіцієнт покриття $k$, де обрано $k$, для попереднього довірчого інтервалу $(1-\alpha)$.

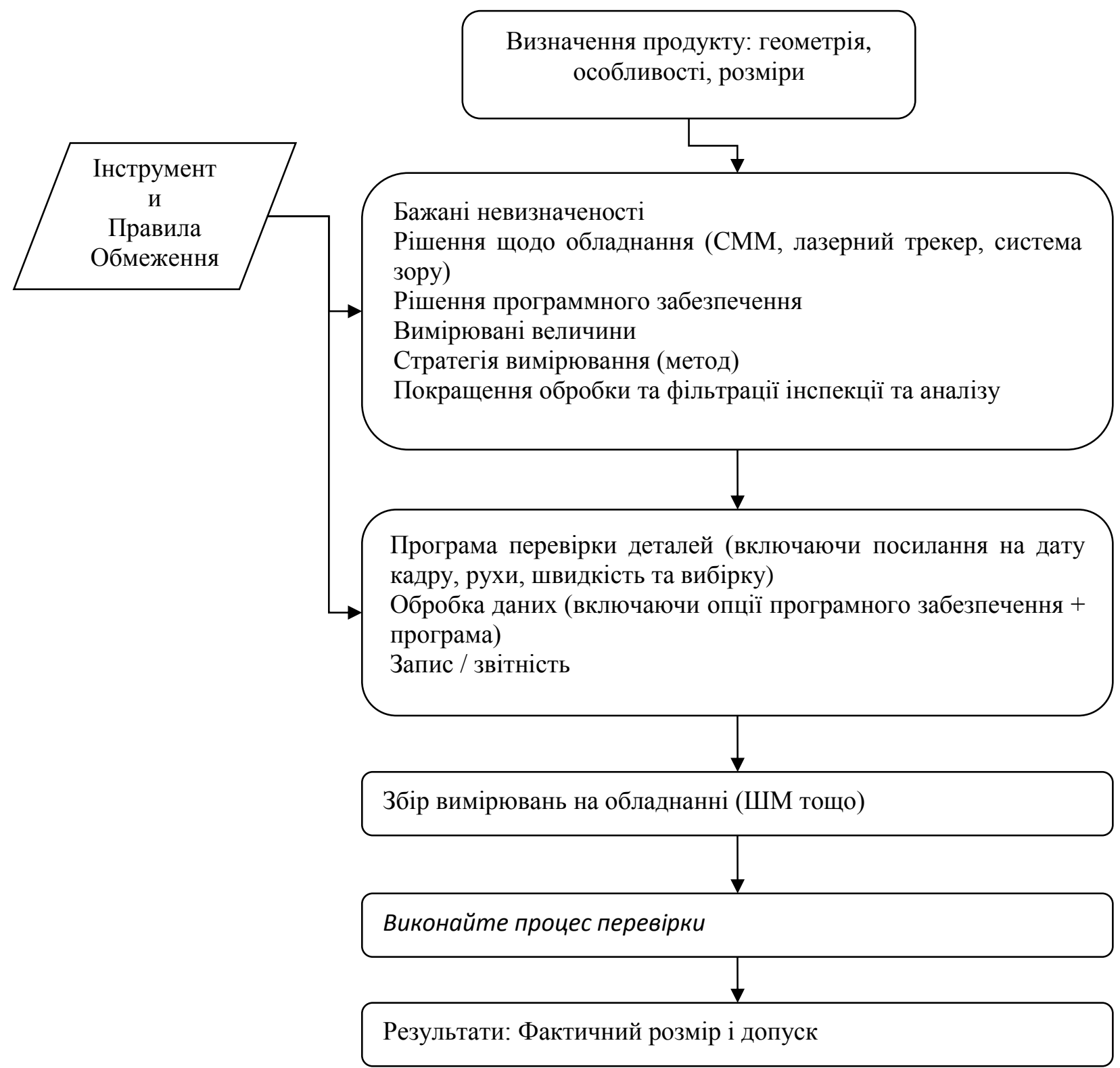

Рис. 1 Модель налаштування процесу перевірки 
Моделювання методом Монте-Карло зазвичай використовується для наближення статистичної поведінки вимірюваної величини в ситуаціях, коли функцію вимірювання неможливо знайти безпосередньо. Для визначення результату вхідні змінні генеруються випадковим чином для кожного моделювання в межах відповідних діапазонів невизначеності. Потім для оцінки невизначеності використовується функція щільності ймовірності вихідного сигналу [10]. Нарешті, у випадках, коли функція вимірювання є дуже складною (або невідомою), емпіричну оцінку можна встановити, використовуючи певні припущення та гіпотези спрощення [11].

Протягом останніх трьох десятиліть координатно-вимірювальна машина побачила прогрес 3 точки зору точності та повторюваності, що, в свою чергу, призвело до підвищення продуктивності. В даний час КВМ відіграє важливу роль у стандартах геометричних вимірювань, які вимагають важливого вимірювального обладнання, необхідного для контролю якості виробництва [12]. Однак, незважаючи на такі вдосконалення, невизначеність може викликати не тільки використовуване обладнання, але й алгоритмічний вибір та прийнята методологія вимірювання [13].

Оцінка невизначеності вимірювань (кількісна оцінка) $є$ вирішальним етапом у характеристиці та підтвердженні узгодженості результатів перевірки [14]. Оцінка невизначеності вимірювань повинна проводитися для забезпечення прогресу в науці вимірювань. Типи помилок, які можуть виникати при вимірюванні геометричних розмірів, можна розглядати, принаймні частково, як функцію технології, що використовується для реалізації системи. Отже, у випадку із застосуванням автоматизованого вимірювання схема подання знань та метод усунення невизначеності створюють значну частину основи для перевірки. Валідація зазвичай розглядається як більш складне завдання, яке не настільки залежить від конкретної технології. Там, де частина автоматизованої системи повинна працювати заздалегідь визначеним чином, наприклад, КВМ, розроблена для вимірювання дожини деталі, вимірювання дійсності є відносно простим. КВМ яка надає невірні результати є недійсною. Інший погляд на валідацію випливає із процесу побудови моделей, зокрема побудови статистичних, економетричних та дослідницьких моделей. Модель - це відображення реальності, яка ніколи не буде «ідеальною».

Існує багато загальних типів недоліків у формі моделі, які можуть бути причиною неточних результатів моделювання: двовимірні моделі, які не можуть представляти ефекти тривимірної варіації; неправильна модель для пружної або пластичної реакції матеріалу; припущення про зв'язок контакту, коли насправді між двома частинами виникає розрив; припущення, що дві частини не рухаються відносно одна одної, коли насправді вони рухаються і розвиваються значні сили тертя; жорсткі граничні умови, які, як виявляється, мають суттєву відповідність тощо. Важливо шукати можливе порушення припущень форми моделі при узгодженні виміряних даних із результатами обчислювального моделювання. Якщо рівняння або параметри моделі змінюються, процес перевірки моделі повинен бути проведений знову. Більше того, якщо параметри були змінені з використанням даних деяких або всіх експериментів з валідації, тоді повинні бути проведені нові експерименти, щоб надати докази валідації. Валідація - верифікація, при якій встановлені вимоги пов'язані 3 передбачуваним використанням. Валідація методик вимірювань - це процес підтвердження, через приведення об'єктивних доказів, як правило, отриманих експериментальним шляхом, того, що методику можна використовувати для певного призначення. Валідацією методик вимірювань, як правило, займаються розробники. В процесі валідації не тільки підтверджують, що методику можна використовувати для конкретного призначення, а й перевіряють ії працездатність на різних стадіях.

Верифікація - надання об'єктивних доказів того, що даний об'єкт повністю відповідає встановленим вимогам. Верифікацією методик вимірювань займається її користувач (лабораторія) при впровадженні методики вимірювань в свою практику. В даному випадку користувач повинен навести докази, що методика вимірювань в лабораторії реалізується згідно встановлених для неї вимог. рис. 2 .

Модель налаштування комп’ютерної результуючої системи геометричних вимірів наведено на

Етапи побудови моделі:

1) Реальна система

- спостереження за реальною системою;

- взаємодія між компонентами;

- збір даних про поведінку;

- концептуальна модель.

2) Побудова концептуальної моделі

- програмне моделювання.

(C) Шорнікова С.В. 
3) Реалізація комп'ютерної результуючої системи геометричних вимірів. дійсності:

Концептуальна основа для перевірки моделі системи геометричних вимірів включає п’ять типів

1. Концептуальний: «ступінь релевантності припущень i теорій, що лежать в основі концептуальної моделі .., для передбачуваних користувачів та використання моделі».

2. Логічний: «здатність формальної моделі правильно і точно описувати проблемну ситуацію».

3. Експериментальний: «якість та ефективність механізму рішення».

4. Оперативний: «якість та застосовність рішень та рекомендацій».

5. Типовий: «достатність, точність, доречність та доступність даних».

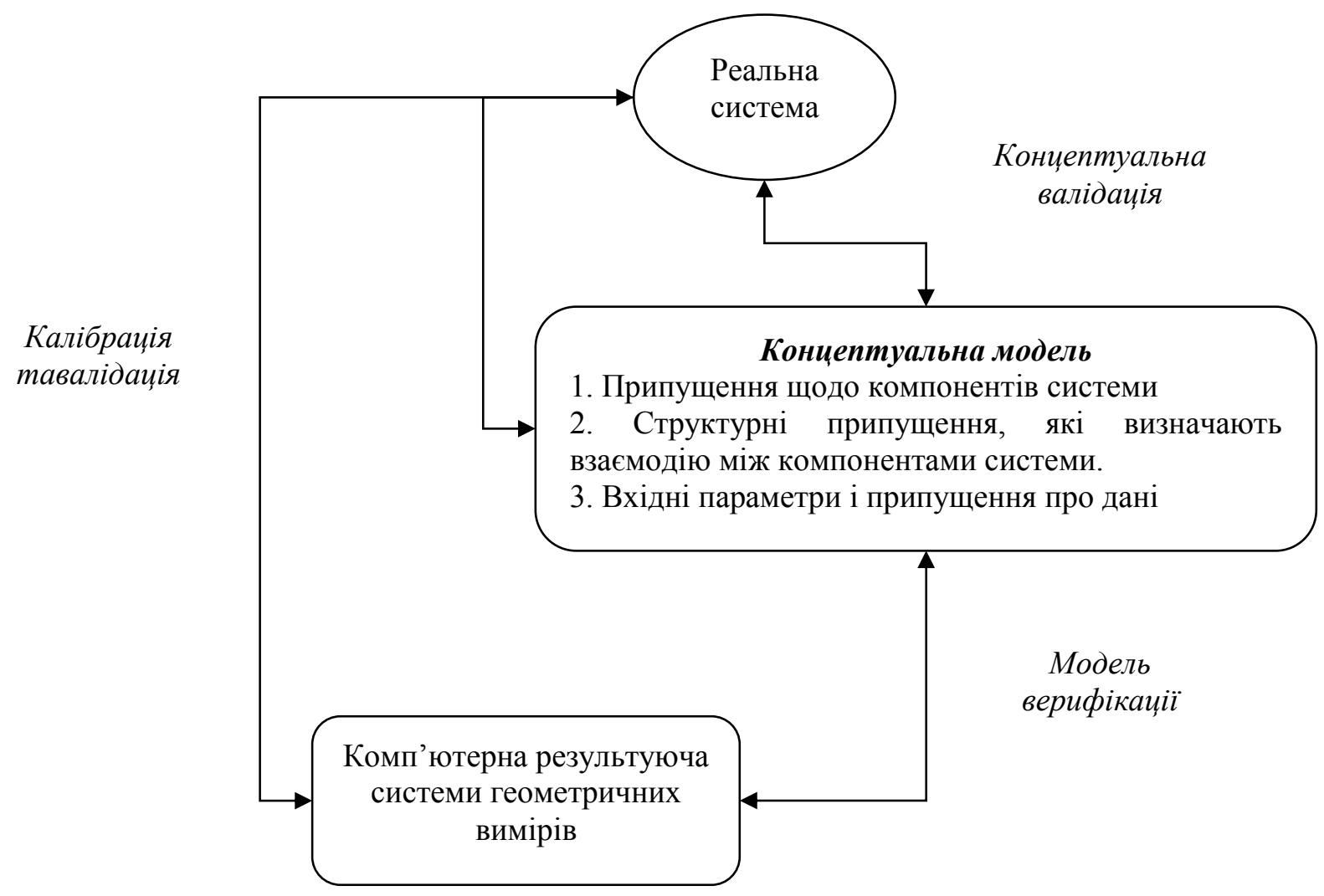

Рис. 2 Модель налаштування комп’ютерної результуючої системи геометричних вимірів

Часто перевірка моделі - це спроба виміряти загальність моделі (наприклад, чи може вона виконуватися з різними наборами даних або за різних припущень). Як правило, перевірку моделі часто ототожнюють з експлуатаційною валідністю - модель оцінюється за якістю їі рішень, проте, абсолютна валідність, заснована на точності рішень, $є$ міфом. Слід врахувати передбачуване використання моделі - модель може бути дійсною для однієї системи, але не для іншої. Отже, концептуальна перевірка та критерії, за якими оцінюється модель, є дуже важливими.

Оскільки модель ніколи не є абсолютно дійсною (або, що стосується цього, абсолютно недійсною), іiі прийняття дуже залежить від передбачуваного використання та користувача. Можна було б очікувати, що чим більш дієва модель, тим вона більш достовірна, але немає гарантії, що діюча модель буде сприйнята як достовірна.

Істинність, обгрунтованість та надійність не гарантують точної, не кажучи вже про корисну систему. Наприклад, система може бути непридатною для використання, оскільки час іiі відгуку занадто повільний або інтерфейс занадто складний. Такі питання, безумовно, є актуальними при оцінці автоматизованих систем для лінійних вимірювань, але загалом валідацію слід розглядати окремо від оцінки, а не лише як частину процесу оцінки, оскільки це $\epsilon$ необхідною умовою для адекватних показників. Погано перевірена система, яка швидко дає неправильні результати лінійних вимірювань, може бути «небезпечною»: поверхнева якість системи може призвести до необгрунтованої довіри та невірних значень.

Для перевірки системи вимірювання геометричних розмірів в умовах виробництва необхідні наступні елементи:

(C) Шорнікова С.В. 
1). Програмний пакет 3D CAT. Використання будь-якого програмного пакету CAT 3D, не повинно змінювати результати, за умови використання методу Монте-Карло.

Етапи моделювання:

1 - Збірка компонентів, де необхідно визначити системи відліку в кожному компоненті, щоб вказати відхилення поплавкового отвору;

2 - Визначення відхилень деталей, де вводяться розміри та допуски, а також радіальні та кутові зміни з'єднання;

3 - Визначення досліджуваної деталі;

4 - Моделювання моделі з урахуванням різних статистичних розподілів, які передбачаються;

5 - Підтвердження результатів.

2). Система вимірювання, яка дозволяє порівняти реальні вимірювані параметри з розмірами, що моделюються в САТ. Це робиться за допомогою лазерного сканера, який відображається на оптичній камері зі стандартним відхиленням калібрування 0,027 мм.

3). Механізм, за допомогою якого можна виміряти різні розміри та допуски. Статистичний розподіл допусків і положення може бути встановлений за допомогою різних вимірювань.

Останнім кроком у процесі перевірки є порівняння значень метрик, обраних для вимірювання порівняння та відповідності між вихідними даними моделі та експериментальними даними, а також оцінка точності моделі. Визначення чи $є$ апробована модель системного рівня адекватною для іiі цільового використання - це програмне рішення та включає як технічні, так і нетехнічні вимоги, такі як графік, наявність, фінансові ресурси, громадськість сприйняття тощо. Зацікавлені сторони, які не $\epsilon$ частиною групи перевірки, зазвичай визначають ці нетехнічні вимоги. Отже, тлумачення адекватності тут обмежене, включаючи лише прийнятну угоду між результатами експерименту та моделювання.

Висновки та перспективи подальших досліджень. У роботі розглянуто принципи валідації та верифікації методик вимірювання геометричних розмірів в умовах виробництва. У визначенні та практиці валідації та верифікації методик вимірювання геометричних розмірів в умовах виробництва є багато відкритих питань. 3 практичної точки зору, витрати, пов'язані з проведенням високоякісної комп'ютерної програми, можуть бути величезними. Отже, довгострокові переваги використання перевіреної моделі для доповнення фізичного вимірювання повинні бути збалансовані із витратами, пов'язаними 3 розробкою моделі та моделлю вимірювання геометричних розмірів в умовах виробництва. Вимоги до ресурсів, пов'язаних з моделлю, вимагають поступового підходу до застосування вимог валідації та верифікації. Потреба у скороченні часу та витрат, пов'язаних 3 масштабними фізичними випробуваннями, сприяє збільшенню залежності від моделювання в області обчислювальної механіки. Цей факт, у свою чергу, мотивує подальший розвиток методології та інструментів для виконання моделі валідації та верифікації. Було визначено декілька сфер, у яких необхідні подальші дослідження та розробки: експертна оцінка та прийняті процедури розробки валідованої моделі; методи та інструменти для проведення кількісної оцінки невизначеності 3 урахуванням як властивої, так і епістемічної невизначеності; методологія встановлення ієрархії перевірки та відповідні вимоги до перевірки моделі; метрики перевірки, показники ефективності та обчислювальні функції для підтримки порівняльних перевірок; способи обчислення помилок та впевненості за допомогою статистичного аналізу результатів обчислень та моделювання, а також методи для визначення оптимальних стратегій перегляду моделі за допомогою аналізу чутливості.

Referehces.

1. CGM 200:2012 International Vocabulary of Metrology - Basic and General Concepts and Associated Terms (VIM 3rd edition)

2. Eurachem, Н. (2016). Придатність аналітичних методів для конкретного застосування. Настанова для лабораторій 3 валідації методів та суміжних питань": за ред. Б. Магнуссона та У. Ернемарка: переклад другого видання 2014 р. Київ: ТОВ" Юрка Любченка.

3. Почекайлова, Л. П. (2013). Валідация методик випробувань. Системи обробки інформації, (3), 85-89.

4. Браилов, А. Ю., Панченко, В. И., \& Косенко, С. И. (2019). Анализ геометрической модели определения параметров недоступной точки объекта. Modern problems of modeling, (14), 38-47.

5. Raffaeli, R., Mengoni, M., Germani, M., \& Mandorli, F. (2013). Off-line view planning for the inspection of mechanical parts. International Journal on Interactive Design and Manufacturing (IJIDeM), 7(1), 1-12.

6. Hovind, H., Magnusson, B., Krysell, M., Lund, U., \& Mäkinen, I. (1). Internal quality control-handbook for chemical laboratories. Nordtest Report Tr, 569.

7. Thompson, M., Ellison, S. L., \& Wood, R. (2002). Harmonized guidelines for single-laboratory validation of methods of analysis (IUPAC Technical Report). Pure and applied chemistry, 74(5), 835-855.

8. MacKinnon, D., Carrier, B., Beraldin, J. A., \& Cournoyer, L. (2013). GD\&T-based characterization of short-range noncontact 3D imaging systems. International journal of computer vision, 102(1-3), 56-72.

9. Van Loco, J., Elskens, M., Croux, C., \& Beernaert, H. (2002). Linearity of calibration curves: use and misuse of the correlation coefficient. Accreditation and Quality Assurance, 7(7), 281-285.

(C) Шорнікова С.В. 
10. Magnusson, B. (2003). Handbook for calculation of measurement uncertainty in environmental laboratories.

11. Lukacs, G., Lockhart, J., \& Facello, M. (2012). Non-contact whole-part inspection.

12. Barbero, B. R., \& Ureta, E. S. (2011). Comparative study of different digitization techniques and their accuracy. ComputerAided Design, 43(2), 188-206.

13. Minguez, R., Arias, A., Etxaniz, O., Solaberrieta, E., \& Barrenetxea, L. (2016). Framework for verification of positional tolerances with a 3D non-contact measurement method. International Journal on Interactive Design and Manufacturing (IJIDeM), 10(2), 85-93.

14. Shrivastava, A., \& Gupta, V. (2011). Methods for the determination of limit of detection and limit of quantitation of the analytical methods. Chronicles of young scientists, 2(1), 21-21. 